\title{
High resolution rainfall projections for the Greater Sydney Region
}

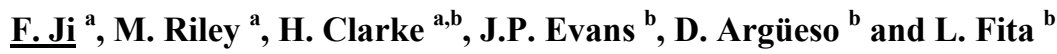 \\ ${ }^{a}$ Office of Environment and Heritage, Department of Premier and Cabinet, New South Wales, Australia \\ ${ }^{b}$ Climate Change Research Centre, University of New South Wales, Sydney, Australia \\ Email:fei.ji@environment.nsw.gov.au
}

\begin{abstract}
Projected changes in the future rainfall of the Sydney metropolitan region were investigated through fine scale ( $2 \mathrm{~km}$ grid) dynamical downscaling from a single global climate model (GCM) simulation using the Weather Research and Forecasting (WRF) regional climate model. Projections of rainfall (20402059) were compared with a reanalysis-driven simulation for the period 1990-2009. There are projected to be changes in rainfall throughout the region with substantial temporal and spatial variation.

The primary mechanisms for these changes were investigated using daily and monthly model outputs. Increased autumn rainfall is primarily caused by greater frequency and intensity of heavy rainfall events during some years. The increased intensity of these rainfall events may be due to greater availability of moisture from the tropics and the interaction between tropical and sub-tropical systems. The influence of the local topography on rainfall patterns is also evident at this scale. However the seasonal variation of change in rainfall is mainly determined by the outer domain and boundary conditions.
\end{abstract}

Keywords: Weather Research and Forecasting (WRF), rainfall projection, downscaling 


\section{INTRODUCTION}

Projections of potential climate change are essential for sustainable natural resources planning and management. They are typically obtained from global climate models (GCMs), with hypothesized scenarios (e.g. for the increase of $\mathrm{CO}_{2}$ concentration, etc.). GCMs are widely used and arguably still remain the best available tools for assessing the responses of the climate system to changes in atmospheric forcing. However, GCMs provide information at a spatial resolution that is too coarse to be used directly in local on ground impact studies or regional planning. Downscaling, for example using a dynamical regional climate model (RCM), is the only option to bridge the gap between the resolutions by producing climate information at a finer scale which can be used at regional and catchment scale impact studies.

The Office of Environment and Heritage (OEH) is developing fine-scale (10 km resolution) climate projections for south-east Australia as part of the NSW and ACT Regional climate modelling (NARCliM) project. Projections at such a fine scale have not been available in NSW before and will provide the detailed information fire and emergency management, water and energy management, agriculture, urban planning and biodiversity management need to adapt to a future climate. For the Sydney climate impact profile, the NARCliM modelling team undertook regional a high resolution (2km) climate projection to 2050 for Sydney Metropolitan Area. Time slices of current climate (1990-2009) and future climate (2040-2059) were simulated using Weather Forecasting and Research (WRF) model (Skamarock et al, 2008).

In this study, the changes in seasonal rainfall for these two time periods were calculated, and the primary mechanisms for these changes were investigated.

\section{MODEL CONFIGURATION}

The version 3.3 of the Advanced Research WRF was used in this study. The simulations used the following physics schemes: WRF Single Moment 5-class microphysics scheme; the Rapid Radiative Transfer Model (RRTM) longwave radiation scheme; the Dudhia shortwave radiation scheme; Monin-Obukhov surface layer similarity; Noah land-surface scheme; the Yonsei University boundary layer scheme and the Kain-Fritsch cumulus physics scheme.

For the $2 \mathrm{~km}$ simulation no cumulus physics scheme is required, and the cloud microphysics scheme plays a more important role warranting the use of a more complex scheme. Several microphysics schemes were run for 1990 conditions and then evaluated against gridded and station based observations. The chosen scheme is the Thompson microphysics scheme [Thompson et al., 2004]. There are 40 vertical atmospheric levels in the $2 \mathrm{~km}$ simulation.

The initial and boundary conditions for the $2 \mathrm{~km}$ simulation were taken from a previously performed and evaluated $10 \mathrm{~km}$ simulation [Evans and McCabe, 2010; Evans and Westra, 2012]. For the present climate simulation, the initial and boundary conditions are from the NCEP/NCAR Reanalysis Project (NNRP) [Kalnay et al., 1996]; and those for the future climate are from CSIRO MK3.5 simulation using the SRES A2 (high) emission scenario [Evans and McCabe, 2013].

Figure 1 shows the high resolution regional climate modelling domain and its topography. There is an altitude gradient within the domain, with low topography close to the coast and high terrain in the western of domain. The land use dataset for present climate was derived primarily from NSW state-wide Land Use data and translated in to the 24 class USGS

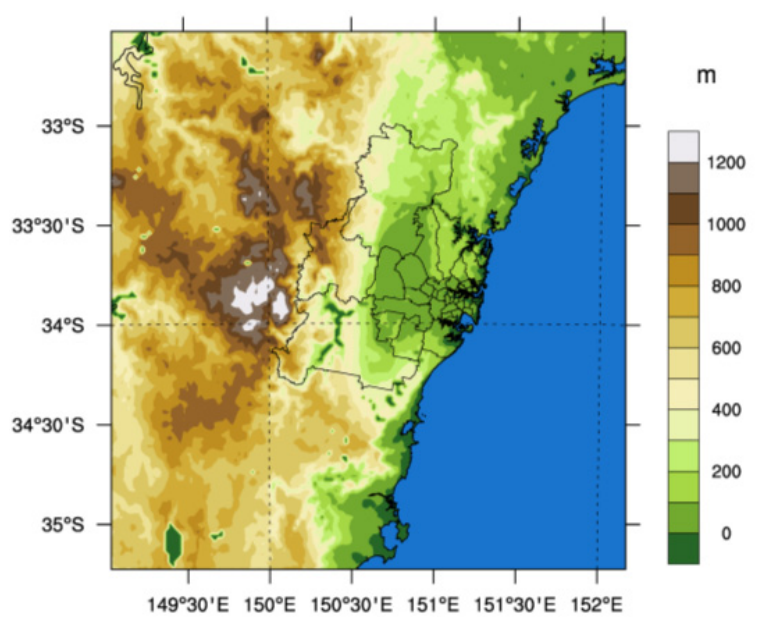

Figure 1. High resolution WRF modelling domain with topography. Black lines indicate the Sydney council regions. classification, and that for future climate contains minor changes to the present land use map based on data from the NSW Department of Planning that indicate areas of urban expansion (Turner 2012). The $2 \mathrm{~km}$ resolution simulations have been examined for the urban heat island effect [Argueso et al., 2013a]. 


\section{RESULTS}

\subsection{Evaluation of WRF simulation}

The rainfall bias correction is based on the distribution of precipitation [Argueso et al., 2013b]. 80 percentile bins were calculated for both the simulation and observation. According to differences between the simulated and the observed percentile ranges, a correction factor is estimated to adjust the accumulated precipitation in each of the bins. The bias corrected rainfall from the CSIRO mk3.5 driven simulation for the period of 19902009 was compared with the gridded rainfall produced in the Australian Water Availability Project (Jones, et al 2009), which are interpolated surface station measurements on a $0.05^{\circ} \times 0.05^{\circ}$ grid. The distributions of observed and simulated seasonal rainfall are shown in Fig 2. The rainfall distribution in the simulation generally matches that in observations for all seasons except for some overestimation for the northwest inland area. The rainfall intensity is slightly stronger in the simulation than observations in the Blue Mountains and Northeast coast. These results indicate that WRF has the capability to capture seasonal rainfall pattern and intensity for the greater Sydney region.
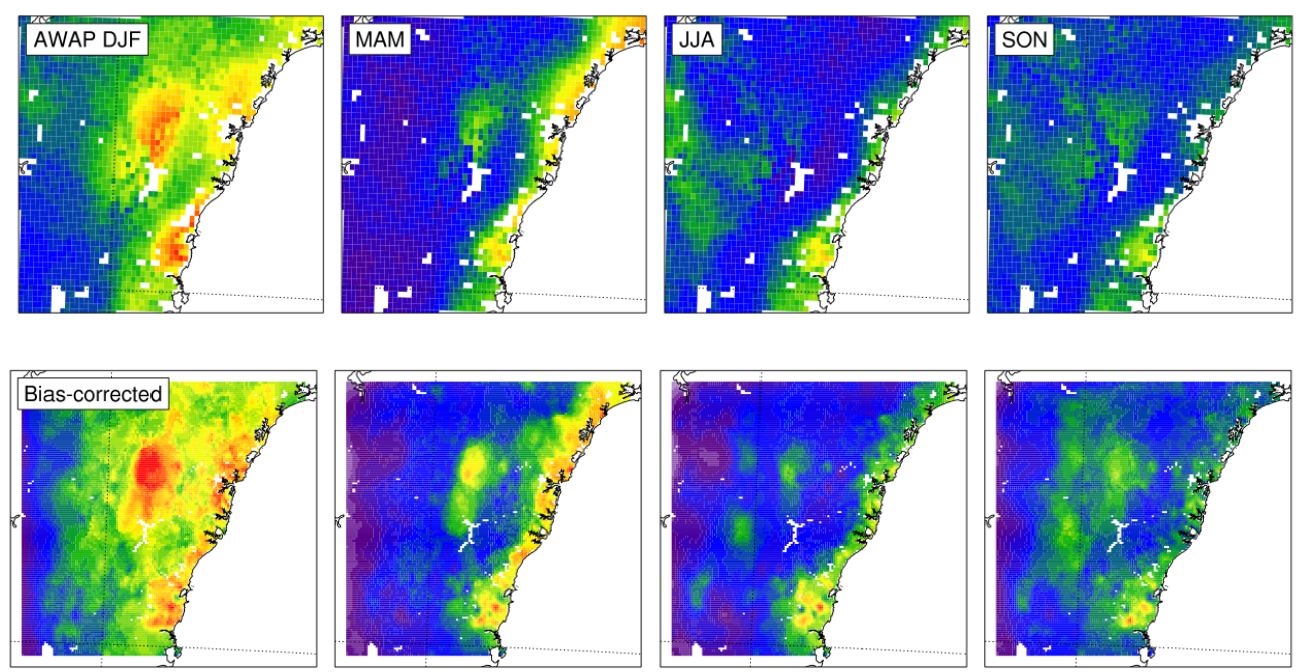

$\mathrm{mm} / \mathrm{month}$

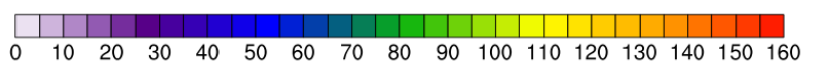

Figure 2. Observed and simulated seasonal rainfall for 1990-2009

\subsection{Changes in annual and seasonal rainfall}

Projected average rainfall for the period 2040-2059 was compared to the average rainfall produced by the model for the period of 1990-2009. Changes in annual and seasonal averages were both investigated. There is
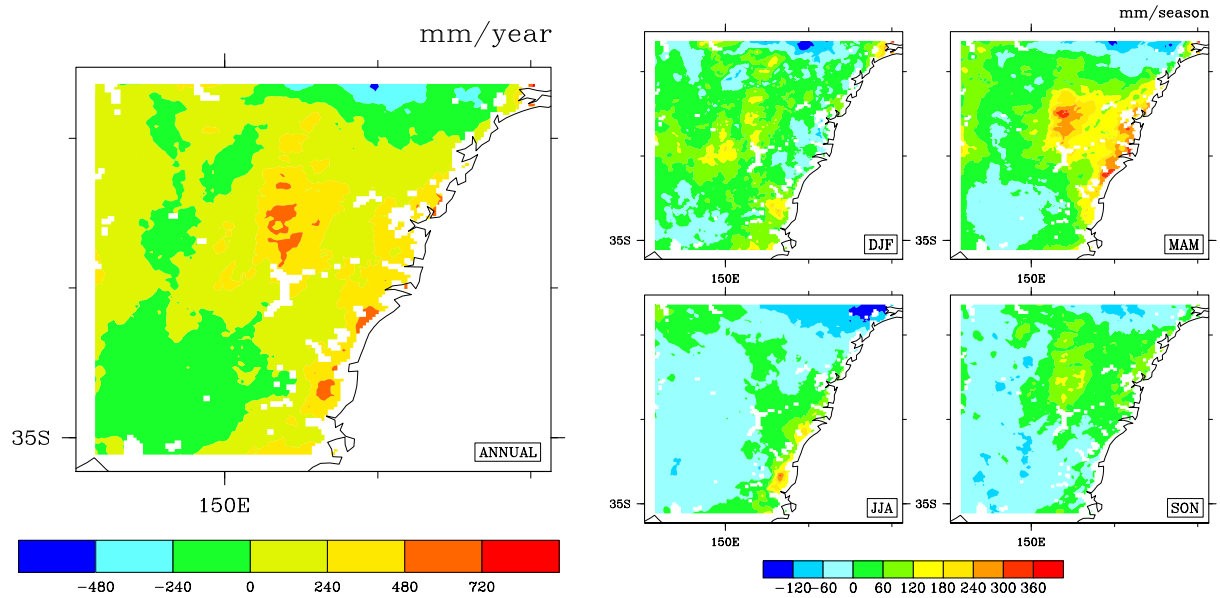

Figure 3. Changes in annual and seasonal rainfall for 2040-2059 relative to 1990-2009 
significant spatial and seasonal variation in projected changes in rainfall throughout the regions. Some areas (Blue Mountains, Sydney, central coast and Illawarra) are projected to have significant increases in annual average rainfall while other may see a decrease (Hunter and Southern Highlands) (left plot in Fig 3). There are also some significant seasonal variations in rainfall with some areas projected to have considerable increases in autumn (MAM) rainfall (right plot in Fig 3). The locations of major changes in MAM rainfall are similar to those for changes in annual rainfall.

\subsection{Primary mechanisms for these changes}

\subsubsection{Seasonal variation of changes in rainfall}

Fig 4 shows the change in seasonal rainfall for the outer $10 \mathrm{~km}$ domain for 2040-2059 relative to 1990-2009. The changes in MAM rainfall are much larger than those for the other three seasons. There is consistency between the outer domain and the inner domain. Running the RCM at $2 \mathrm{~km}$ resolution can dramatically enlarge the magnitude of these changes but still follow the seasonal pattern of outer domain $(10 \mathrm{~km})$. This indicates that the seasonal variation of change in rainfall is determined by the coarse resolution RCM simulations.

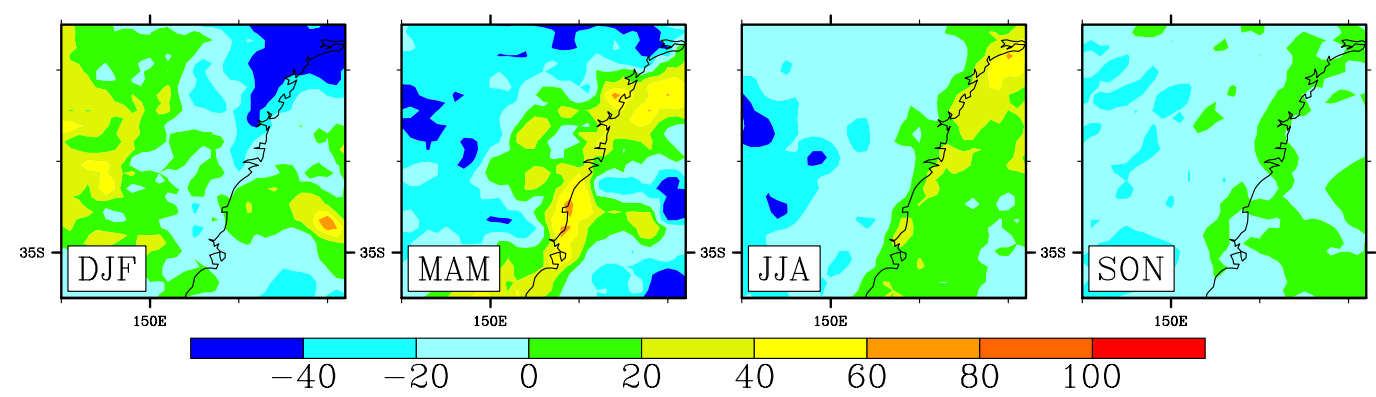

Figure 4. Change in seasonal rainfall for outer domain (10Km resolution) for 2040-2059 relative to $1990-2009$

\subsubsection{Major increase in the MAM season}

The correlation between change in rainfall amount and change in other relevant seasonal variables was firstly compared. The best correlation comes from maximum rainfall rate for 10, 20, 30 and 60 minutes. Fig 5 shows the change in maximum 10 and 30 minute rainfall rate for 2020-2040 relative to 1990-2010. These indicated that the main positive rainfall changes in MAM are possibly caused by extreme rainfall events.
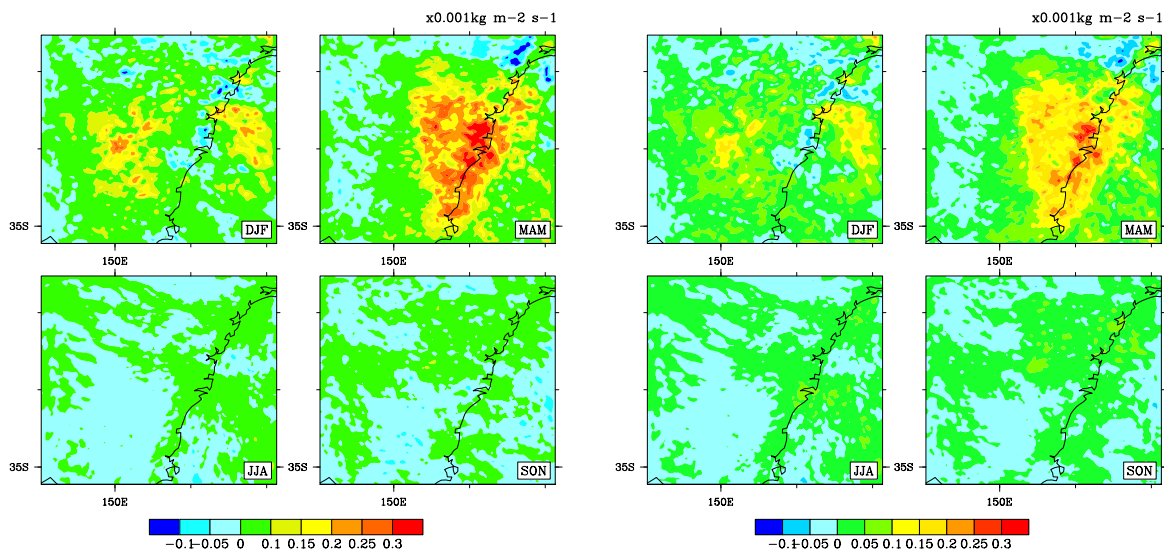

Figure 5. Change in maximum 10 and 30 minute rainfall rate for 2020-2040 relative to 1990-2010

The MAM seasonal rainfall for each of the future 20 years are analysed to locate the maximum changes in rainfall in MAM season. The results shown in Fig 6 indicate that this seasonal increase is not uniform across years. MAM rainfall in 2045, 2054, 2056, 2057, 2058, and 2059 is much higher than other years. MAM rainfall in these years contributes the majority of the positive changes in rainfall showed in Figure 3. Therefore, the daily rainfall and rainfall events for MAM season in those years were fully investigated. The 
results show that the higher MAM rainfall was mainly caused by increased intensity of extreme rainfall events. For an example, rainfall from one extreme rainfall event ( $2^{\text {nd }}$ to $9^{\text {th }}$ March 2045) contributes more than $90 \%$ of rainfall in March 2045 .

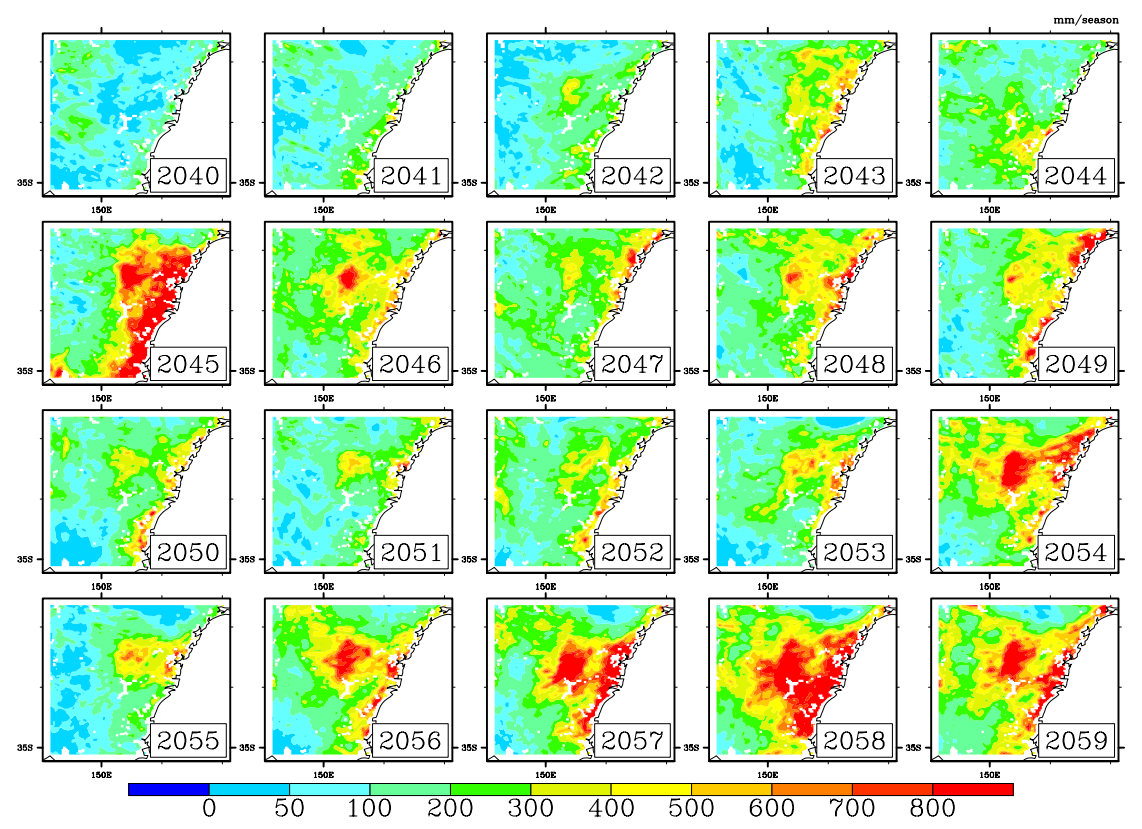

Figure 6. Rainfall in MAM season for the future 20 years (2040-2059)

The change in frequency of rainfall is important in determining these changes as well. The total days with daily rainfall above five different thresholds (10, 25, 50, 100 and $200 \mathrm{~mm})$ within MAM season were investigated for the two time periods, including the change between them (Table 1). Not only are there increases in each of the five threshold categories, but the magnitude of change increases for each the threshold.

Table 1. Total rainfall days in MAM season for the two 20-year periods.

\begin{tabular}{|c|c|c|c|c|c|}
\hline Maximum Daily rainfall & $>10 \mathrm{~mm}$ & $>25 \mathrm{~mm}$ & $>50 \mathrm{~mm}$ & $>100 \mathrm{~mm}$ & $>200 \mathrm{~mm}$ \\
\hline $\begin{array}{c}1990-2009 \\
\text { (days) }\end{array}$ & 1139 & 784 & 493 & 216 & 34 \\
\hline $\begin{array}{c}2040-2059 \\
\text { (days) }\end{array}$ & 1375 & 1096 & 769 & 402 & 142 \\
\hline \begin{tabular}{c} 
Change (\%) \\
\hline
\end{tabular} & 20.72 & 39.80 & 55.98 & 86.11 & 317.65 \\
\hline
\end{tabular}

To further explore exactly how extreme rainfall events are simulated in WRF, the extreme rainfall event from 2-9 March 2045 was investigated. It is quite clear that the extreme rainfall is caused by a low pressure weather system. The low system brought strong water vapour flux from ocean to land, which results in extreme high vapour mixing ratio (Fig 7). The water vapour mixing ratio during the extreme event is much higher than mean monthly values for March 2045, which is also much higher than mean annual values for 2045. This indicated that it is unusually extremely wet during the period of the event.

The weather patterns from the outer large domain $(50 \mathrm{~km}$ and $10 \mathrm{~km}$ resolution) show consistency between the outer domain and the inner domain. The larger scale results indicate the interaction between tropical and sub-tropical regions. The extreme water vapour mixing ratio observed during the event is caused by the water vapour transferred from the tropical region (not shown). 
The distributions of water vapour mixing ratio for different time scales indicated the influence of local topography especially Great Dividing Range and Blue Mountain. The vertical velocity during the events also showed the influence of the terrain (not shown).

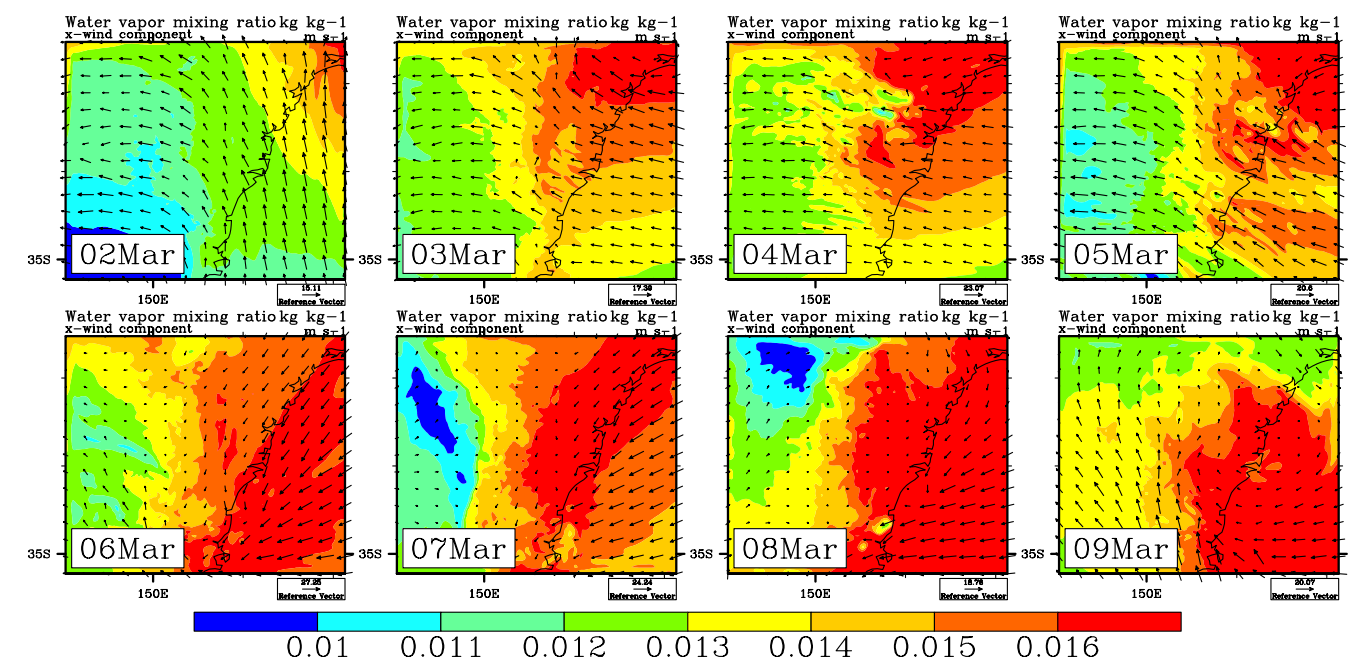

Figure 7. Water vapour mixing ratio and wind vector at low level for the event.

\section{DISCUSSION AND CONCLUSIONS}

The results for this study show that there is likely to be changes in rainfall throughout the region with significant spatial variation. Some areas are projected to have significant increases in annual average rainfall while other areas are projected to experience decreases. There are also some significant seasonal variations in rainfall with some areas projected to have considerable increase in autumn rainfall. The increase in autumn rainfall is primarily caused by increased frequency and intensity of heavy rainfall events during some years. The increased intensity of these rainfall events may be due to increased availability of moisture from the tropics and the interaction between tropical and sub-tropical systems. The influence of the local topography on rainfall patterns is also evident at this scale, justifying the use of fine-scale downscaling.

It has been reported widely in literature that, as a result of climate change, the frequency and intensity of extreme weather conditions are likely to increase. Therefore, being able to simulate extreme rainfall events could be an advantage of the dynamical downscaling method. However, the magnitude of the change should be further investigated. As the dynamical downscaling is finally downscaling from GCMs, the many published studies have confirmed that the major uncertainties in downscaling are sourced from GCMs (Teng, et al 2012; Chiew et al 2010). The results shown here are downscaled from one GCM and therefore represent one possibility of future climate conditions.

\section{ACKNOWLEDGMENTS}

This work is made possible by funding from the NSW Environmental Trust for the ESCCI-ECL project, the NSW Office of Environment and Heritage backed NSW/ACT Regional Climate Modelling Project (NARCliM), and the Australian Research Council as part of the Discovery Project DP0772665 and Linkage Project LP120200777. This research was undertaken on the NCI National Facility in Canberra, Australia, which is supported by the Australian Commonwealth Government.

\section{REFERENCES}

Argueso, D., J.P. Evans, L. Fita and K.J. Bormann (2013a) Temperature response to future urbanization and climate change. Climate Dynamics, doi: 10.1007/s00382-013-1789-6.

Argueso, D., J.P. Evans and L. Fita (2013b) Precipitation bias correction of very high resolution regional climate models. Hydrology and Earth System Sciences Discussions, doi:10.5194/hessd-10-8145-2013. 
Chiew, F.H.S., D.G.C. Kirono, D.M. Kent, A.J. Frost, S.P. Charles, B. Timbal, K.C. Nguyen, G. Fu (2010), Comparison of runoff modelled using rainfall from different downscaling methods for historical and future climates. Journal of Hydrology., 387(1-2), 10-23. doi:10.1016/j.jhydrol.2010.03.025.

Evans, J. P., and M. F. McCabe (2010), Regional climate simulation over Australia's Murray-Darling basin: A multitemporal assessment, Journal of Geophysics Research, 115(D14114), doi:10.1029/2010JD013816.

Evans, J.P. and M.F. McCabe (2013) Model resolution impact on regional climate and climate change using WRF over south-east Australia. Climate Research, 56:131-145, doi: 10.3354/cr01151.

Evans, J.P. and S. Westra (2012) Investigating the Mechanisms of Diurnal Rainfall Variability Using a Regional Climate Model, Journal of Climate, 25, 7232-7247, doi:10.1175/JCLI-D-11-00616.1.

Kalnay, E. et al. (1996), The NCEP/NCAR 40-year reanalysis project, Bulletin of the American Meteorological Society, 77(3), 437-471.

Skamarock,W., Klemp, J. B., Dudhia, J., et al (2008), A Description of the Advanced Research WRF Version 3, NCAR TECHNICAL NOTE, NCAR/TN-475+STR

Teng, J., J. Vaze, F. H.S. Chiew, B. Wang and J.M Perraud (2012), Estimating the relative uncertainties sourced from GCMs and hydrological models in modelling climate change impact on runoff, Journal of Hydrology, 13, 122-139, doi: 10.1175/JHM-D-11-058.1

Thompson, G., R. M. Rasmussen, and K. Manning (2004), Explicit forecasts of winter precipitation using an improved bulk microphysics scheme. Part I: Description and sensitivity analysis, Monthly Weather Review, 132(2), 519-542.

Turner, G. (2012), Report on Methodology to Produce Sydney $2 \mathrm{~km}$ Contemporary \& Future (2030) Land Cover Data, NSW Office of Environment \& Heritage, Sydney, Australia. 